\title{
Harmony and disharmony as the architectural appearance features of the city
}

\author{
Irina Mayatskaya ${ }^{*}$, Batyr Yazyev, and Svetlana Yazyeva \\ Don State Technical University, 344022, Rostov-on-Don, Russia
}

\begin{abstract}
Architecture in the world obeys the laws of symmetry and asymmetry, harmony and disharmony, and, of course, the principles of the golden section. The use of digital technology and innovation allows modern architects to design the structures that have a harmonious style and harmoniously fit into the environment. It is necessary to widely introduce the three-dimensional modeling methods into practice for more effective modern cities' architectural appearance creation.
\end{abstract}

\section{Introduction}

The architecture of a modern city is very diverse, has multifaceted and unique forms that are characteristic of this particular urban environment [1-4]. It should be noted that the architecture of many cities in the world is subject to the laws of harmony and disharmony.

The architecture of the city, like music, is a combination of harmony and elements of disharmony. But over time, these elements can already be considered as the development of harmony, but already on a new environment perception. So, the contemporaries of Beethoven did not always understand his music, they believed that it was devoid of harmony. But time has shown exactly how genius his music is and completely obeys the laws of harmony. It is necesary to understand these patterns of our world development, including architecture development (Fig.1, 2).

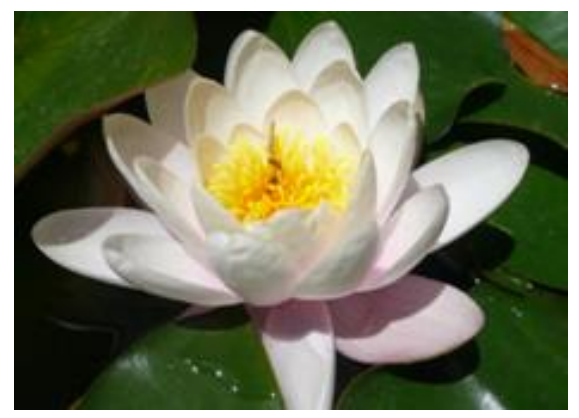

Fig. 1. Beauty and harmony of the lotus flower.

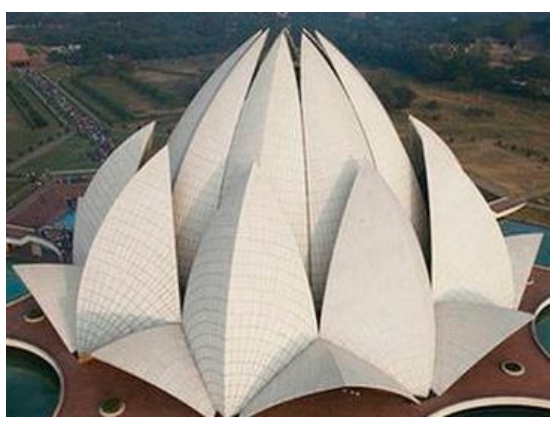

Fig. 2. Beauty and harmony of the Lotus Temple.

\footnotetext{
* Corresponding author: irina.mayatskaya@mail.ru
} 
Harmony in architecture is not only the well-established traditions of building structures, but also a look into the future with a change in the rules in accordance with the inner state of a person and his environment [5-7]. Digital technologies and innovations help to create the buildings and complexes of structures based on an understanding of the harmony and disharmony of our world. It is the three-dimensional modeling methods that make it possible to create digital $3 \mathrm{D}$ models for the designed object analysis.

\section{Harmony in architecture - symmetry and asymmetry}

Symmetry is proportionality and balance in the arrangement of parts of the whole in space, and asymmetry is the opposite property of symmetry [8]. In architecture, such types of symmetry as axial, mirror, rotary portable can be used. These types are widely used both in modern buildings and in architectural monuments (Fig. 3-5) [8-10]. A historic building in London is shown in Fig. 5, which shows the typical symmetrical arrangement of architectural forms relative to the central axis of the building. Fig. 6 shows a mansion with asymmetry in both external appearance and internal space. But this building, designed by the architect Fyodor Osipovich Shekhtel, has a harmonious style.

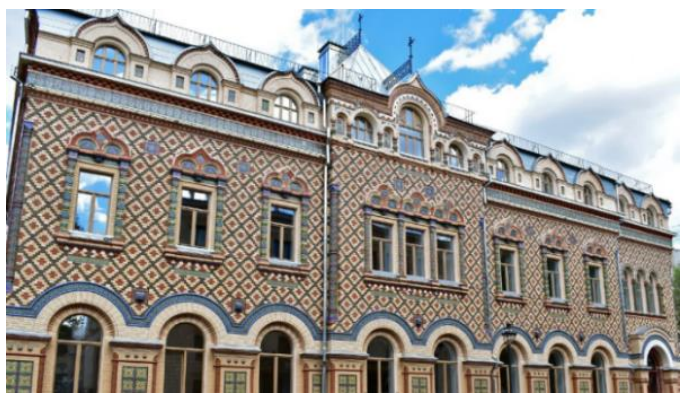

Fig. 3. Lopatina's mansion, Moscow.

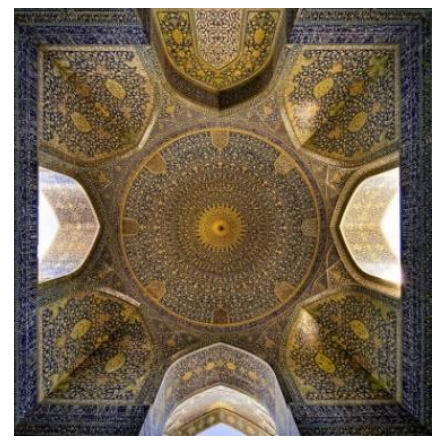

Fig. 5. The inner space of the mosque dome with 8 th order symmetry.

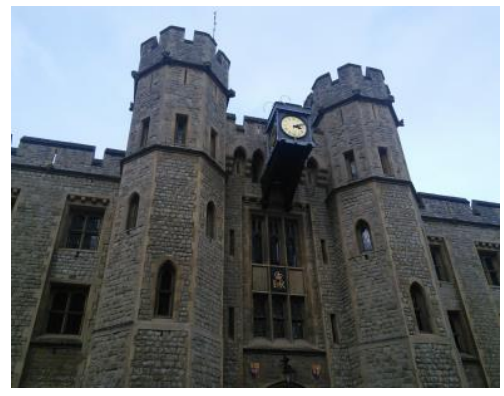

Fig. 4. Part of the London Tower structure with axial symmetry.

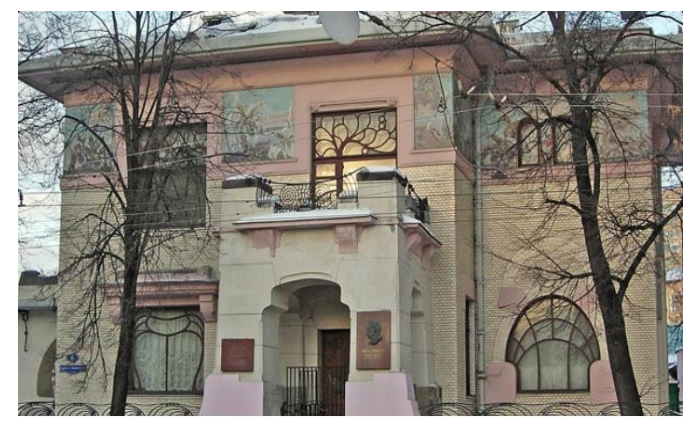

Fig. 6. The mansion of S.P. Ryabushinsky with an asymmetric arrangement of architectural elements.

A starfish is an example of a living organism with a 5th-order rotational symmetry (Fig. 7). Reflection in water of the surrounding world is an example of horizontal symmetry in nature. Nature is almost symmetrical, but not absolutely symmetrical, but only approaches the reference form. Mirror symmetry is most common in nature and architecture (Figure 8). Symmetry is perceived by a person as a manifestation of natural laws and, of course, this perception is also transferred to architectural forms $[10,11]$. 


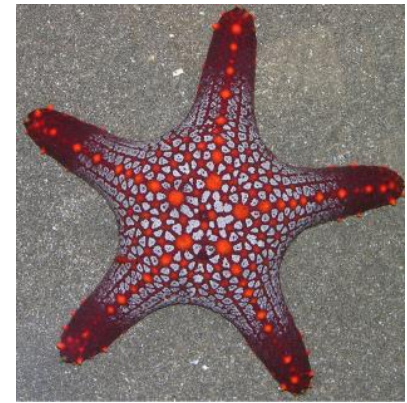

Fig. 7. Starfish with 5 th order rotational symmetry

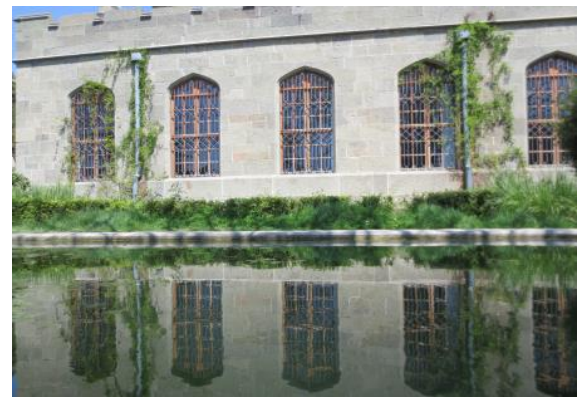

Fig. 8. Reflection in the form of a historic building facade, Crimea.

Symmetry is often used in world monuments of architecture as a means of creating unique complexes [9]. Symmetry manifests itself in the architectural appearance of the building, making it complete and rhythmic. After all, rhythm is also a means of architectural composition, which can develop both vertically and horizontally. The main types of rhythmic series in architecture are metric, drum, pulsating, wavy, dynamic (Fig. 9, 10). It is the rhythm that makes it possible to more vividly manifest the principles of symmetry and asymmetry in the design of a wide variety of structures complexes.

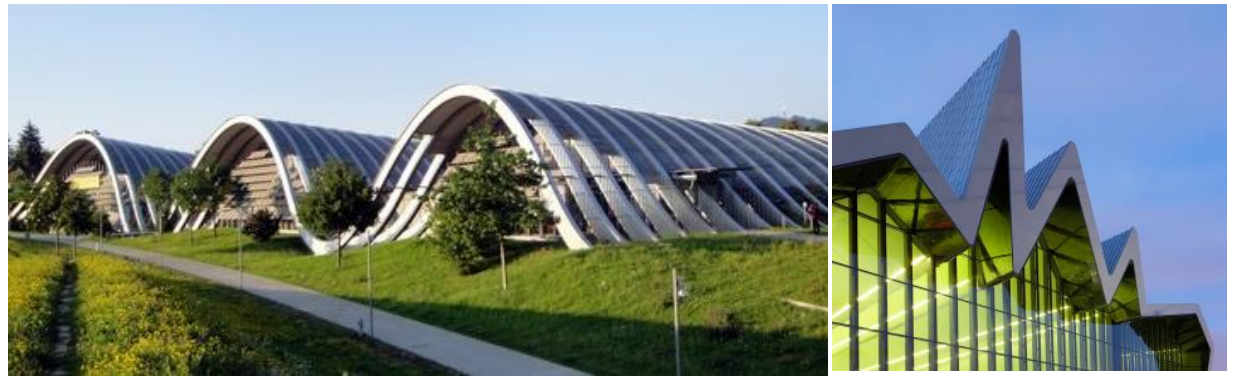

Fig. 9. Paul Klee Center in Börne (undulating rhythm).

Fig. 10. Riverside Museum of Transport in Glasgow (dynamic rhythm).

Objects with a symmetrical arrangement of shapes are more stable than those with asymmetric parts of the structure. And symmetrical structures are always perceived as more harmonious, perfect and are considered to be more beautiful [12]. But the unity of symmetrical and asymmetrical elements in the structure of the building give an opportunity to create simply amazing structures (Fig.11,12).
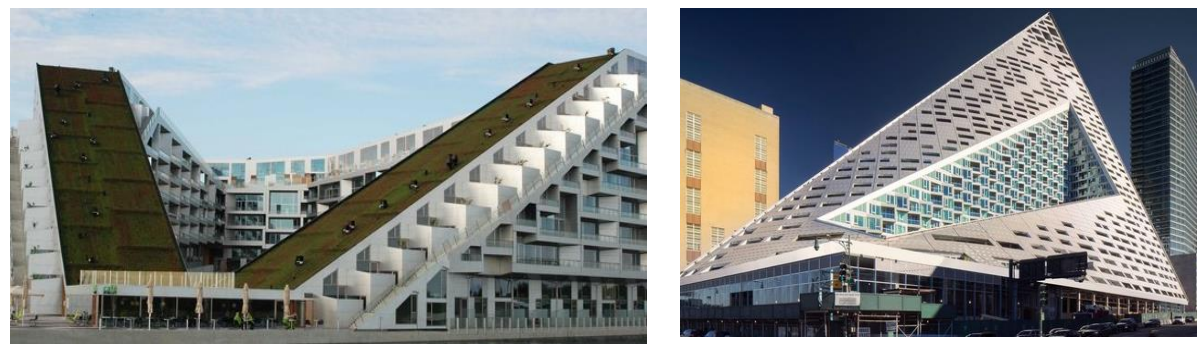
Fig. 11. Residential complex "8 House" by Fig. 12. Residential complex "Via 57 West" architect B. Ingels in Copenhagen. by architect B. Ingels in New York.

The architecture of the Taj Mahal and other famous mosques is based on absolute symmetry. Each element of the building harmoniously fits into the structure of the temple complex (Fig. 13). The inner space is also subject to harmony, creating a unique appearance of world architecture monuments (Fig.14).

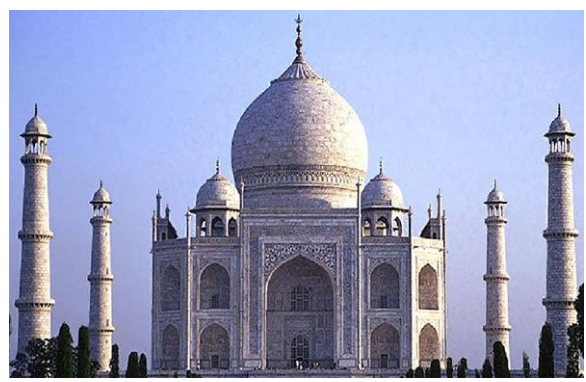

Fig. 13. Temple complex Taj Mahal, India.

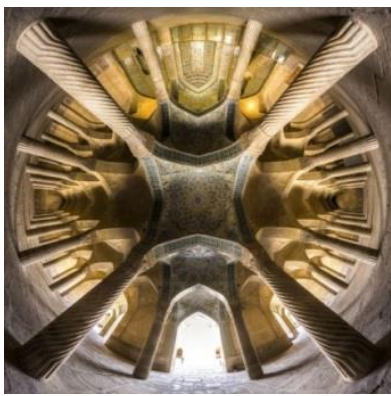

Fig. 14. Internal symmetry of the mosque space in Iran.

Symmetry and asymmetry are two sides of the harmonious appearance of the building, the combination of which makes the object unique and unrepeatable (Fig. 15). An example of such a combination is St. Basil's Cathedral in Moscow (Fig. 16).

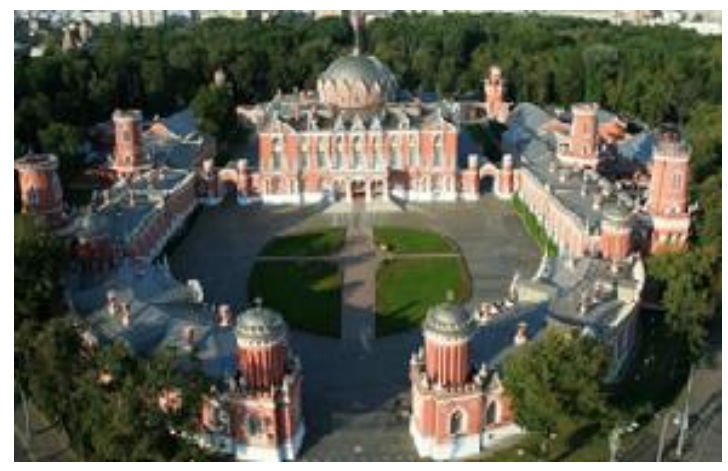

Fig. 15. Petrovsky Travel Palace in Moscow.

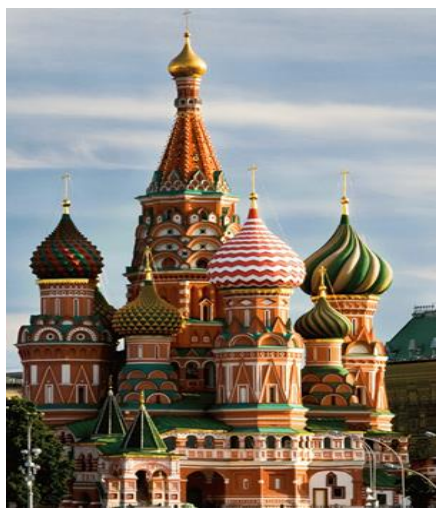

Fig. 16. Cathedral of St. Basil the Blessed in Moscow.

The golden ratio is an asymmetric symmetry, this is the rule of general proportion, which creates a universal composition of the entire complex of structures [13,14]. An asymmetric composition of architectural forms is also harmonious if the laws of the golden section are fulfilled. Symmetry is characterized by the laws of geometric equality of parts of a whole, and asymmetry requires the unity of parts that are asymmetrically located in space, but possessing the balance of composition and a holistic perception of the entire structure. Architects in their work strive for harmony, for the creation of truly beautiful and unique structures.

\section{Harmony and fractality of architectural forms}


In nature and in architecture, division into symmetrical parts and golden proportions is often used $[5,13,14]$. In parts, the repetition of the structure of the whole is manifested. The principle of the golden ratio consists in dividing a segment into unequal parts in such a way that the entire segment refers to the larger part as the larger part itself refers to the smaller one, or the smaller segment refers to the larger one as the larger one to the entire segment:

$$
\frac{a}{b}=\frac{b}{a+b} ; \quad b=0.618(a+b) ; \quad a=0.382(a+b) .
$$

Geometric constructions of dividing a segment in the golden ratio can be carried out using a triangle with a leg ratio of $1: 2$ (Fig. 17).

The golden ratio is characterized by the general proportion rule, examples of which are also the golden rectangle and golden spiral, which are geometric fractals. The golden rectangle is the squares inside the rectangle with the side equal to the Fibonacci numbers (Fig. 18). The golden spiral is a sequence of connected quarter circles inscribed inside squares with the sides equal to the Fibonacci numbers (Fig. 19). In nature, the golden spiral is found in the structure of the sunflower head with seeds and in the structure of other plants, for example, in cones and cacti (Fig. 20-22) [6].

The essence of the Fibonacci number sequence is that each number in this sequence is obtained from the sum of the two previous numbers. The numbers forming this sequence are: $0,1,1,2,3,5,8,13,21,34,55,89,144$. When dividing any number in the sequence by the number in front of it in the row, the value is $1.618(\Phi=1.618)$.
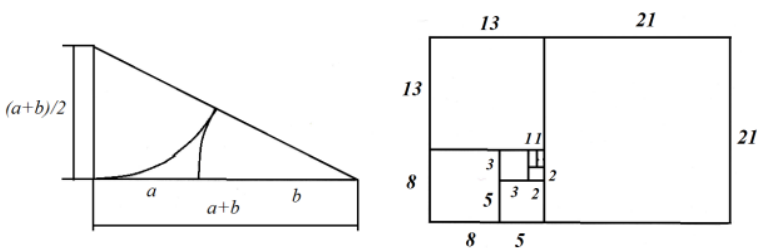

Fig. 17. Graphical construction of the golden ratio.

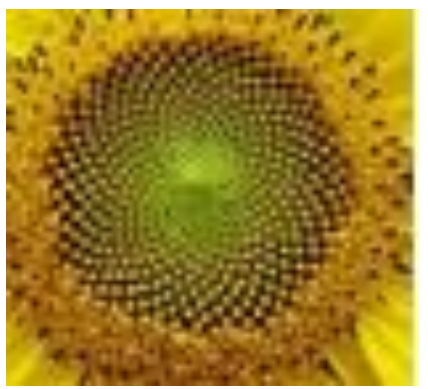

Fig. 20. Spirals of a sunflower. rectangle.

Fig. 21. Spiral pine cones.

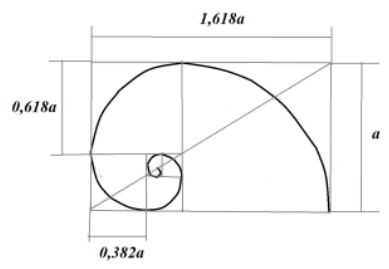

Fig. 19. Building the golden spiral.

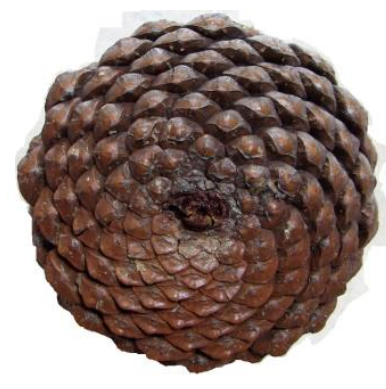

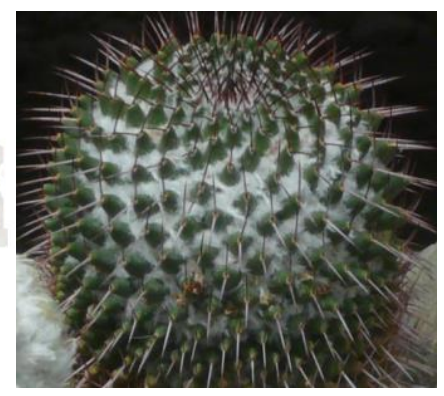

Fig. 22. Cactus spirals.

The golden ratio theory is a simpler presentation of the geometric and algebraic fractals construction by means of geometric structures and a sequence of Fibonacci numbers [9, 15 18]. But it was this theory that was widely used by architects in the construction of unique structures of the past (Fig. 23). But the development of mathematics in the 20th century was fruitful. The theory of fractal geometry was developed in the works of Benoit Mandelbrot 
[19]. Further development of the theory of fractals became possible thanks to digital technologies and computer technology development (Fig. 24).

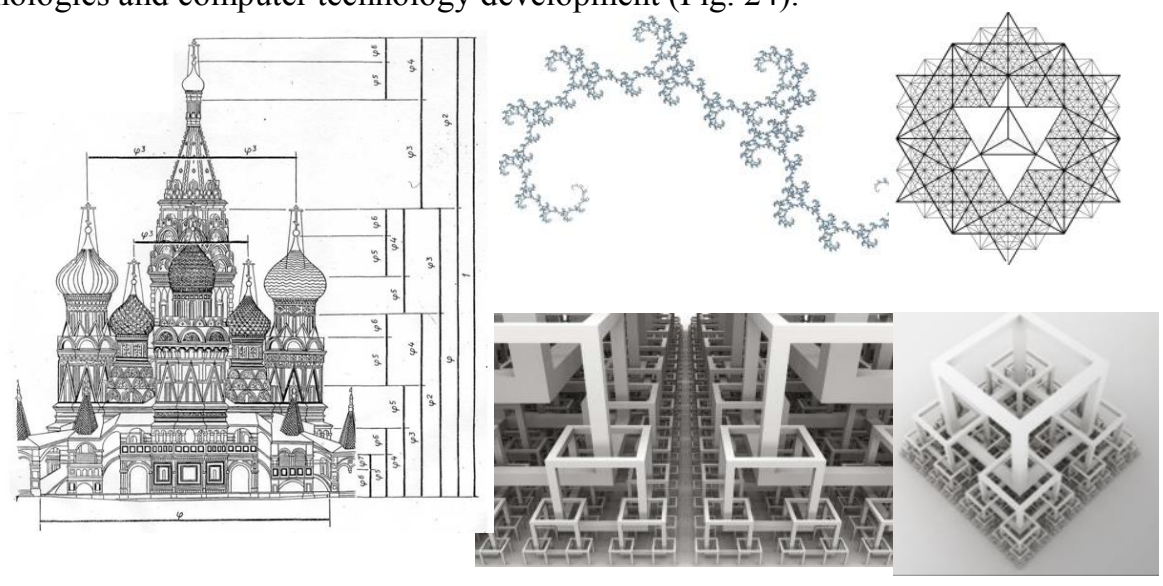

Fig. 23. Golden proportions when

Fig. 24. Geometric fractals.

building

St. Basil's Cathedral in Moscow

The golden spiral is closely related to cycles. Cyclic structures are studied in fractal theory, which includes chaos theory. The structure of the DNA molecule also uses the principle of the golden ratio. This principle can be traced in art, nature, architecture. It is a perfection manifestation of the whole and its parts.

\section{Harmony and disharmony in the architectural elements of structures}

Modern buildings have a rather complex structure of space organization. Therefore, it is not enough to use only symmetry in the architectural composition of a building. A complex composition combines symmetry and asymmetry, harmony and disharmony, straight or curved continuous lines in the design and fractality [15-18]. In modern architecture, all these properties are most often found, creating a generally unique look [20,21].

It is very important that the architectural appearance of the city has a style that would combine historical traditions and modernity. When deciding to build modern structures in historic quarters, it is necessary to consider the issues of the environment harmony and disharmony. Even interesting projects can introduce an imbalance in urban development, and then already built buildings have to be demolished. An example of such an imbalance is the House of Soviets in Kaliningrad, the demolition of which has already been decided (Fig. 25, 26).

The use of asymmetric forms in architecture introduces some imbalance in the overall plan of the structure, but if the measures and methods of fractal geometry are observed, unique buildings can be created. The subordination of the architectural ensemble parts creates structures that have a harmonious appearance $[5,16,20]$. Buildings should not only have harmonious forms, but also harmoniously fit into the urban look and natural environment. [6, 21].

To understand harmony in modern architecture, it is possible to use 3D modeling of designed objects. And already on the basis of the constructed models, it is possible to analyze the geometric harmony of the form at the project stage. In this case, it is possible to make 
certain changes, taking into account the harmonization of the architectural object volumetricspatial form.

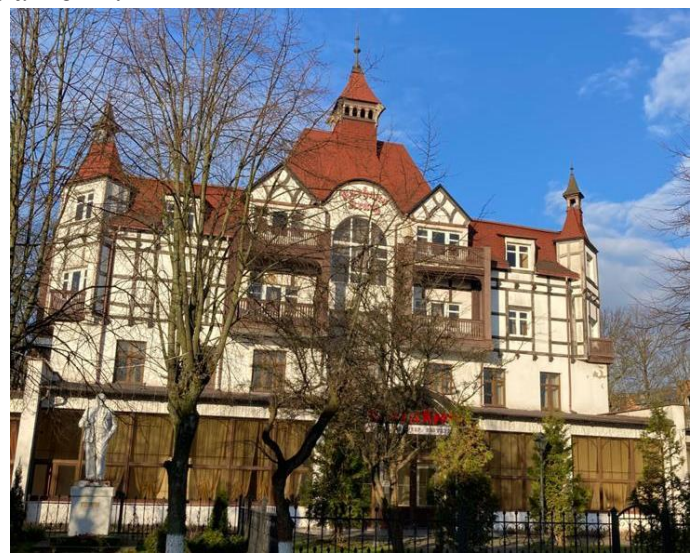

Fig. 25. The architectural appearance of Kaliningrad.

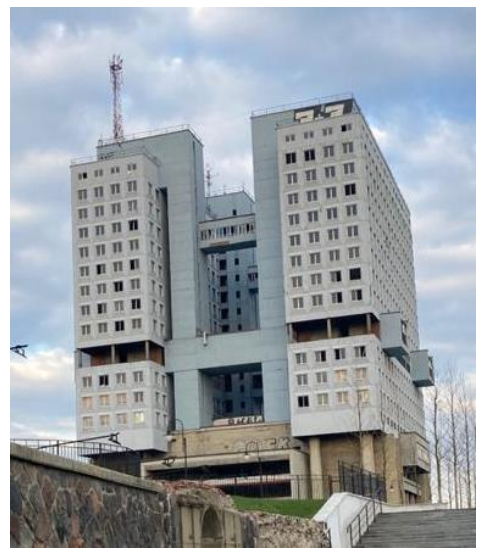

Fig. 26. House of Soviets in Kaliningrad.

\section{Conclusion}

Symmetry and the golden ratio are considered to be one of the harmonizing laws of nature that order the structure of the world around us. And the development of fractal geometry made it possible to look differently at nature, at architecture, at the consciousness of the person himself and his perception of the world around him. This expanded the possibilities of architects in their work. These or those types of compositions develop, changing over time, with the advent of new technologies and materials in the construction of structures. Chaos that leads to destruction must be avoided. The harmonious development of architecture affects the consciousness of a person, his harmonious perception of the world, which will not destroy nature, traditions and the world around him, including unique buildings of the past and present.

We must preserve our architectural heritage and create the architecture of the future based on the harmonious development of the world. Then human consciousness will be less accessible to negative thoughts. And maybe there will be fewer world military conflicts. It is necessary to develop a collective immunity to the barbaric attitude towards architecture, towards nature and towards a human.

\section{References}

1. V.P. Maksakovsky, World cultural heritage (Peter Publishing, 2002)

2. H. Stierlin, Encyclopaedia of world architecture (Publishing Evergreen, 1994)

3. E.E. Viollet-le-Duc, Architecture. World history of architecture (AST Publishing, 2018)

4. P.P. Gnedich, World architecture, (Publishing house Eksmo-Press, 2012)

5. Ya.D. Glinkin, Architectural harmony methods, (Stroyizdat Publishing, 1979)

6. I.A. Mayatskaya, V.D. Eremin, S.B. Yazyeva, Construction and architecture 7 (1), 91 96 (2019)

7. S.B. Yazyeva, I.A. Mayatskaya, Materials Science and Engineering 1083, 0012018 (2021) 
8. G. Weil, Symmetry (LKI Publishing, 2007)

9. I.A. Mayatskaya, S.B. Yazyeva, B.M. Yazyev, Construction and industrial safety 12 (64) 29-32 (2018)

10. N.I. Smolina, Traditions of symmetry in architecture (Stroyizdat Publishing, 1990)

11. M.V. Shubenkov, Structural patterns of architectural shaping (Architecture-C Publishing, 2006)

12. N.I. Vasilyev, Harmony in art (Publishing Fenix, 2013)

13. V.I. Korobko, Golden ratio and problems of harmony of systems (Rostizdat Publishing Saint Petersburg, 2015)

14. I.Sh. Shevelev, M.A. Marutaev, I.P. Shmelev, Golden ratio: three views on the nature of harmony, (Stroyizdat Publishing, 1990)

15. M. Batty, P. Longley, Fractal Cities: a geometry of form and function (Publishing Academic Press, San Diego, 1994)

16. B.M. Yazyev, I.A. Mayatskaya, S.B. Yazyeva, S.B. Yazyev, Materials Science and Engineering, 698 (2), 022087 (2019)

17. I.A. Mayatskaya, B.M. Yazyev, S.B. Yazyeva, Construction and architecture 9 (1) (30), 66-70 (2021)

18. S.B. Yazyeva, I.A. Mayatskaya, I.V. Kashina, A.N. Nesterova, Materials Science and Engineering, 698 (3), 033046 (2019)

19. B. Mandelbrot, Fractal geometry of nature (Institute for Computer Research Publishing, 2002)

20. I.A. Mayatskaya, V.D. Eremin, B.M. Yazyev, Construction and architecture 9 1(30), 7680 (2021)

21. I.A. Mayatskaya, B.M. Yazyev, S.B. Yazyeva, Materials Science and Engineering 1083 0012028 (2021) 